\title{
La poetización del anonimato en la ciudad*
}

Fecha de recepción: 2 de octubre de 2014

Fecha de aprobación: 28 de febrero de 2015

\section{Resumen}

La poetización de la ciudad descubre la nueva tragedia que vive el hombre. Poetas colombianos como Luis Vidales, Rogelio Echavarría y Mario Rivero dan cuenta, con su lírica, del anonimato y la incomunicación que vivimos, pues, la ciudad impone un código de mutismo en la que los hombres se encuentran sin hablarse, las relaciones se establecen a través de la desconfianza y el extrañamiento por lo que miles de personas paradójicamente están juntas pero solas. La ciudad capitalista hace que el hombre cosifique al otro, enmarcándose las relaciones en un plano pragmático e individualista, preocupándose tan sólo por el dinero, la ganancia y la utilidad, razón por la que los transeúntes deshumanizan sus relaciones y viven la ciudad bajo el afán. El poeta las critica retratando ese nuevo vértigo y ritmo despersonalizado bajo un nuevo estilo; el collage.

Palabras Clave: ciudad, fragmentación, collage, capitalismo, sociedad, soledad, consumo, transeúnte y cosificación.

* Artículo de reflexión sobre la poética de la ciudad, inscrito en el Grupo Senderos del Lenguaje de la UPTC.

Citar: Díaz Sáenz, S.L. (julio-diciembre de 2015). La poetización del anonimato en la ciudad. La palabra, (27), 189-200.

\section{Said Leonardo Díaz Sáenz}

Universidad Pedagógica y Tecnológica de Colombia filosofíasaid@gmail.com

Said Leonardo Díaz Sáenz, filósofo de la Universidad Sergio Arboleda, magister en Literatura de la Uptc. 


\section{Poetization of anonymity in the city}

\section{Abstract}

The poetization of the city reveals a new human tragedy. The Colombian poets Luis Vidales, Rogelio Echavarría and Mario Rivero give lyrical testimony of anonymity and incommunication in cities which impose a code of mutism where human beings no longer speak to each other, establishing relations through distrust and estrangement. The city is the place where thousands of people live together but continue being alone. The capitalist city makes man objectify the other, and sets relationships on a pragmatic and individualist level, where the only concern is money, wealth and utility. For this reason pedestrians live de-humanized relationships, as they walk their paths in a constant hurry. The poet criticizes them, by capturing this new vertigo and de-personalized rhythm under a new style: collage.

Key words: city, fragmentation, collage, capitalism, society, solitude, consumption, pedestrian, objectification.

\section{La poétisation de l'anonymat dans la ville}

\section{Résumé:}

La poétisation de la ville révèle la nouvelle tragédie que vit l'homme. Certains poètes colombiens tels que Luis Vidales, Rogelio Echavarría et Mario Rivero rendent compte, à travers leur poésie, de l'anonymat et de l'incommunication dans lesquels nous vivons. En effet, la ville impose un code de mutisme à travers duquel les hommes se rencontrent sans se parler ; les rapports s'établissent à travers la méfiance et l'étonnement, ce qui fait que, paradoxalement, des milliers de personnes sont ensemble, mais seules. La ville capitaliste entraîne l'homme vers la réification d'autrui. Les relations s'inscrivent sur un plan pragmatique et individualiste. Les individus ne sont préoccupés que par l'argent, le profit et l'intérêt. Ils déshumanisent leurs rapports et vivent dans une société sous tension. Les poètes critiquent ces rapports, en dépeignant ce nouveau vertige et ce rythme dépersonnalisé à travers un nouveau style : le collage.

Mots clés: ville, fragmentation, collage, capitalisme, société, solitude, consommation, individus et réification. 
Este es un artículo que in- manera: tenta conjugar y, por supuesto, analizar los temas que confluyen entre el poeta y la ciudad, importante relación para destacar dentro del marco del análisis literario y sus respectivas significaciones.

Por ello, no es fortuito que se creen poemas al estilo collage en los que se resalte la sensación de la soledad y el símbolo de la sombra. Estos poemas muestran la fragmentación del sujeto y la búsqueda de un sentido que nunca se encuentra; así mismo, la evocación de cosas que se desvanecen. Al final todos estos asuntos convergen en la ciudad y en la experiencia que podemos vivir en ella.

\section{La soledad y la sombra}

La soledad, que es narrada poéticamente por Luis Vidales, se evidencia en el inicio del poema La Sombra muerta, donde el escritor se encuentra buscando la soledad, luego decide ir a la casa en vez de ir a un café y, bajo las dos sombras del cuerpo y la existencia, mata a la primera al encender la luz, y a la otra, la sombra de la existencia, la apuñala contra la pared. Al final abandona la casa para siempre, y allí deja asesinada a la sombra. Su tedio se ve reflejado en la imposibilidad de encontrarse y de reconocerse a sí mismo, por ello en el poema que viene a continuación se evidencia de esta

\section{La sombra muerta}

¡Oh fue una tragedia dolorosa! el bullicio del café me torturaba de tal modo, que sólo en la soledad podría hallar mi completa liberación. Salí precipitadamente, y vestido con el disfraz de la noche me interné por la callejuela que pasa por frente de mi casa.

El gato, ronroneante como un viejo acordeón, había hecho su envoltorio sobre una poltrona del vestíbulo. Fuera de la musiquilla de su asma, en toda la casa reinaba el largo silencio de un desierto. Hasta el tiempo había dejado de bailar el reloj. Pero con el ruido que yo levanté al entrar, el gato se despertó y me pareció ver un correcto saludo en el estiramiento de su desperezo.

¡Ah!, ¡esto que pasa en mi cerebro es un recuerdo macabro que no he de olvidar nunca! Allí está latente como si hubiera ocurrido ayer, hoy o, peor aún, en este instante que agoniza. El gato, lleno de delicia, vino a frotarse contra mis piernas; y entonces... ¡mi espíritu se infló como un sapo!

Yo quería estar solo. Subí las escaleras que conducen a mi habitación y tras de mi cerré la puerta para que nadie pudiese importunarme. ¡Qué supremo deleite! ¡Qué saludable alegría la de reunirse solo! Por un instante me sentí el más feliz de los hombres. Pero fue sólo un instante.

Luego, de reojo, noté que a mi lado había algo que alentaba acompasadamente con mis ademanes. Giré súbitamente sobre los talones y allí, sobre la pared de mi cuarto, se destacaba mi sombra, ¡como una segunda persona de mí mismo, como un ente que se nutría de $\mathrm{mi}$ propia vida!

Todavía hubo en mi cerebro un relámpago de reflexión. Torcí el botón de la luz y quedé envuelto en una densa tiniebla. Hubo otro momento de felicidad. Pero tan sólo otro momento. Ya no me estorbaba la sombra del cuerpo, pero la sombra del alma se hizo tan grande como la noche. No sé qué rumoró en mi oído. $\mathrm{E}$ ignoro que hubiera sido de mí sino me apresuro a encender el globo de la luz.

Empezó entonces mi batalla con la sombra de la pared. Hice un ademán de desesperación, y la sombra, con inaudito descaro, manifestó su vitalidad levantando los brazos en la misma actitud de los míos. Me escondí tras 
la cortina, y ella se escondió conmigo. Di vueltas en redondo del cuarto y ella me siguió como un relámpago negro. Ya no hubo en $\mathrm{mi}$ cerebro campo a la reflexión. Los nervios se me volvieron nudos en debajo de la piel. Lleno de ira, empuñé el férreo cortapapel que reposaba tranquilo en mi escritorio, y con paso lento, de asesino, inmensamente agrandada sobre el muro, y la cosí a puñaladas. ¡No exhaló la más leve queja! ¡Aquello fue como si mi mano hubiese asesinado al silencio!

Desde aquella noche, abandoné para siempre la casa donde se desarrolló mi primer crimen. ¡Tal vez allí, contra la pared de mi cuarto-como una mariposa de la media noche- esté todavía clavada la sombra muerta! (Vidales, 2004, pp. 23-25).

Abandona la casa y queda exiliado de ella para siempre. Ese lugar donde el hombre se puede recoger del mundo, sin embargo la casa se vuelve un lugar pesado, huella y señal del fracaso de un sujeto que no se puede encontrar consigo mismo.

El poema muestra la paradoja de la soledad en todo el recorrido de su personaje, empieza con un hombre que va a su casa a disfrutar de la soledad: "el bullicio del café me torturaba de tal modo, que sólo en la soledad podría mi completa liberación". En la búsqueda de la felicidad el poeta deja la multitud, los otros humanos significan aquí una carga, además la compañía está llena de bullicio, por lo que, opuestamente, la soledad estará cargada de silencio, "en toda la casa reinaba el largo silencio de un desierto". La búsqueda de la felicidad, que era la del silencio y la soledad, sólo se disfruta un instante, “iQué saludable alegría la de reunirse solo! Por un instante me sentí el más feliz de los hombres. Pero fue sólo un instante”. En la primera parte del poema, la soledad es un signo que evoca la felicidad, el silencio y el encuentro consigo mismo.

Luego, todo esto cae y lo pone en conflicto con sus dos sombras que le pesan, al mismo tiempo el sujeto va perdiendo los estribos, conducido por la desesperación, abandonará a la razón: "Todavía hubo en mi cerebro un relámpago de reflexión" y poco después: "Ya no hubo en mi cerebro campo a la reflexión". La contingencia de este sujeto entonces lo pone en malestar con el mundo y consigo mismo, se desespera con ambos.

El tedio por el otro se da cuando el poeta expresa que le molesta el bullicio, aquí se debe acentuar que el otro no es una voz, ni un ser que escucha, es decir, el otro pierde sus rasgos de individuo porque lo hacen olvidarse de sí mismo y sentirse un hombre masa. En el bullicio, las personas se ponen las máscaras, se habla de todo y de nada, lo que refleja que la conversación es un medio para salir del vacío, la soledad y la búsqueda del sentido.

En el bullicio, las palabras de los unos y los otros no se tocan, son la algarabía de los distraídos que quieren olvidarse de sí mismos con el otro, las drogas o el alcohol. En esta medida, el café no es lugar de diálogo donde pueda develar mi existencia ni la del otro, sino el lugar donde me puedo olvidar de la pesadez y de la rutina para ser, por un instante, un hombre leve.

¿Qué es lo que permite su encuentro con la sombra? Un mundo masa, donde se cruza con miles de personas que siempre son ajenas; al final no queda otra que dar la vuelta y encontrarse consigo mismo, sin embargo no logra calmar el vacío del alma, ya que no encuentra sosiego cuando está en el café, ni tampoco siquiera al regresar a su casa, reflejando su perturbación, pues, la soledad es una de las paradojas de la modernidad. Las personas viven en una sociedad rodeados de miles de personas pero, a la vez, sin siquiera distinguirlas. $\mathrm{Al}$ final de la historia, el personaje huye del encuentro con su sombra, la mata. 
En la ciudad los encuentros son desencuentros, cuando en las calles las personas chocan hombro contra hombro para interponer su mirada desafiante y fría con la del otro, determinándose como extraños; luego viene la ponzoña, el veneno que sienten por dentro, de reconocerse realmente solos.

Tanto la soledad como la compañía presentan un estado de ambigüedad, por eso es que el personaje no se hallaba en el café ni en su casa. Su búsqueda no queda clara ni resuelta y se convierte en una sensación borrosa de desesperación. Su estado anímico es paradójico porque no puede disfrutar de la compañía ni tampoco de la soledad, al parecer porque no cumple en plenitud ninguna de los dos, por consiguiente el personaje queda como suspendido sin ser ni una cosa ni la otra. Verdaderamente, como lo dice el poema, es una dolorosa tragedia.

Así, el hombre-masa tiene una paradoja, no se encuentra consigo mismo ni con los demás. La ambigüedad es parte esencial de este hombre que en ningún lugar puede hallarse, ni en el bullicio del café, ni dialécticamente en el silencio de su casa. Escapa del café porque quiere estar consigo mismo, como debería permanecer todo poeta pero al final huye de ese silencio. Cuando el hombre mata a su sombra y vuelve a la calle es como si hubiera aniquilado a la soledad y al silencio que le permite reflexionar, escribir, hacer poesía, erigir un arte, perfeccionar su alma.

El poema hace un retorno a la calle; la decisión final es no volver para siempre a la casa, es decir, al lugar que buscó huyendo del café para desplegar su sombra y hallar la plenitud del silencio por un momento, el poema queda aparentemente inconcluso, ¿qué le deparará la calle de la cual había huido para encontrarse consigo mismo? Tal vez, un café bullicioso que le sirva para olvidarse de él, para perderse en el ruido, un limbo alienado donde no toque ni el infierno ni el cielo, donde esté solo sin estarlo.

Finalmente, se interna en la calle donde supuestamente se encuentran a otros, para elegir la simulación de la compañía, y abandonar para "siempre" la casa; la soledad, para ser un hombre-masa que ya nunca más buscará sosiego en sí mismo y en las multitudes, y decidirá quedarse en la simulación de la compañía, abyecto en un mundo en donde los opuestos se confunden.

$\mathrm{Su}$ primer crimen consiste en matar a la sombra, simbólicamente a la soledad a la posibilidad de encontrarse consigo mismo, a desplegarse en el ensimismamiento, crimen que también desarrolla la actual sociedad capitalista, la cual ha instaurado la masificación, el consumismo y la alienación para que los humanos aborrezcan su soledad y así, cuando en su casa sientan el silencio, prendan la radio, el televisor o vean una película donde solo predomina la acción: estarán utilizando todos los medios posibles para no sentirse solos.

El lenguaje y la compresión se desarrollan en la comunicación entre unos y otros, de ahí la importancia de esta que se crea a través del juego dialéctico de la conciencia, entre el "yo" y el "otro". Sin embargo, vivimos en un mundo en el que se ha roto los lazos con los demás, apenas quedan vestigios de comunicación, festejos hipócritas. Una sociedad donde el otro es apenas un ruido porque los seres humanos se han dejado de escuchar y de reconocerse para vivir en el anonimato.

Por otro lado, en el poema El enigma se encuentra reflejada la ambigüedad del hombre equilibrado-desequilibrado, el primero es el hombre de éxito, una persona que tiene claro el sentido de la vida y acciona sus pasos según el confort de la sociedad, el segundo es el bohemio que va saliendo de la taberna, tambaleando, sin rumbo y en caos. Esta dicotomía lo lleva a la angustia de la misma existencia, de establecer que la kinestesia de sus pasos lo puede llevar al mismo suelo, a aterrizar en el pavimento caótico de la 
vida, al sinsentido. Tirado en el suelo, desesperado, sin la ayuda de nadie, pues todos caminan con tal grado de perfección que en su trasegar no lo reconocen, entonces, despierta y se encuentra en la patología de los diferentes, de los que ya no pertenecen a esa larga fila de alienados.

Los valores mercantiles son los que han establecido los límites de la locura, fundamentando un canon de comportamiento de hombre de progreso que simboliza al equilibrado. Sus acciones todas se dirigen a las ganancias y el dinero, bajo esa elocuencia, el hombre se sitúa con su reloj bajo el lema "el tiempo es oro". Yergue su fisionomía bajo el ímpetu del progreso, logrando los ideales aburguesados de la clase media, estandarizando su accionar, mas este hombre sufre una metamorfosis kafkiana y deja de serle útil a la sociedad, pues, ebrio, pierde el concepto de finalidad capitalista y se vuelve un estorbo a los transeúntes equilibrados.

\section{El enigma}

-Perdóneme usted, caballero- me dijo el hombre del gabán y del sombrero de copa, que iba gentilmente montado en unos pantalones a rayas-.Le ruego me permita...

Y con un gesto pulcroquizá demasiado espiritual- me presentó su cigarrillo sin encender.

-Con sumo gusto, le contesté. Y mientras prendía el pitillo en la candela del cigarrillo, pude ver que entre sus manos pálidas la cigarrillera se sonreía... se sonreía fantásticamente.

-Guarde usted esa caja- le dije secamente como dirigiéndome a un subordinado-. Tiene un gesto macabro que no puedo resistir.

El hombre obedeció en silencio. Lo vi palidecer. Luego me miró al rostro. Y eludiendo la conversación que indudablemente se iniciaba, soltó su voz, timbrada de un desenfado delicioso:

-Mientras usted iba delante de mí, caballero, he observado- complacido en un principio y al fin delirante de admiración- el maravilloso equilibrio que posee usted, a pesar de que- déjeme usted que se lo diga- su manera de andar tiene un cierto vaivén que realmente luce muy a las claras señalados puntos de contacto con el ridículo. Su equilibrio de usted puede llegar a ser muy hermoso. Está en potencia, como dicen esos señorones de anteojos que la gente llama lógicos. ¡Ah!, caballero! Ese equilibrio - sutilizado por medio de una educación esmerada- sería la más encantadora vertical.

En aquel momento dos hombres salían de la taberna frontera. Asiéronse del brazo y atravesaron por entre las sombras exhibiendo unas grietas irreparables en sus equilibrios. El hombre dejó de hablar, pero sus ojos desmesurados seguían fijos en los míos. Bajo el fluido de sus miradas, mi cuerpo se iba insensibilizando como sumergido en las ondas de un agua soporífera. De pronto, el desconocido tendió hacia mí sus brazos, que había desnudado hasta los codos, y con las manos abiertas comenzó a sustraer de mi cuerpo unos hilos semiinvisibles- . Formó un enorme ovillo, por lo que presumo. Se lo guardó en el gabán, y después de mirar a su alrededor, seguro de que nadie lo veía, huyó como un perseguido por la avenida somnolenta...

Yo caía sin sentido. No sé cuántas horas pasaron sobre mi cuerpo agostado. Cuando me levanté no podía sostenerme. El mundo tambaleaba bajo mis pies. Sin embargo, la memoria se despejó paulatinamente hasta que llegó un momento en que lo comprendí todo. ¡Aquel hombre me había robado el 
equilibrio!

Clamé, clamé bajo la noche, pero nadie se compadeció de mi desgracia. Desde entonces - como un ebrio consuetudinario- sin encontrar el absintio que me libre de este mal, cansado, infinitamente cansado, ¡Voy tambaleándome por la vida! (Vidales, 2004, p. 58).

\section{transeúnte y el otro}

El lenguaje de la vista es la episteme del transeúnte de la ciudad y la fuente de su conocimiento, lo que generará fragmentación y soledad en el sujeto. ¿Hasta dónde se puede conocer al otro a través de una mirada sensible y estética? ¿Hasta dónde llega el goce y la melancolía de la mirada?

Entonces queda cerrado el diálogo con el otro, la comunicación y un posible sentido. El puente que pueden construir las personas para dejar de ser extraños es a través del diálogo, medio que permite que se puedan conocer las historias de los demás con sus problemas y sus luchas, lo que denota su verdadera condición humana. La sociedad, sin embargo, manifiesta opuestamente lo contrario, un desinterés general por conocer a los demás, al final, sólo quedan las personas frente a frente como extrañas o maniquíes.
La vista no podrá rescatar lo que el diálogo puede dar, sólo puede husmear, detenerse a ver lo que está expuesto en la vitrina o detrás de una ventana, entonces si no hay puentes entre el sujeto y los otros, el ser humano se vuelve un ser atomizado y fragmentado, un cristal roto que no puede volverse a unir, seres que habitan el mundo sin vínculos frente a los demás y a la sociedad.

Así en el siguiente poema Rogelio Echavarría expresa:

\section{Libertad}

La soledad, mi solidaria en el teatro y en el parque, la soledad en la sopa fría y en los comensales del restaurante,la soledad a la mesa sentada, en la barra del bar y en la moneda disoluta y en mi corazón impar (Echavarría, 2004, p. 39).

El poeta se encuentra solo en los diferentes sitios de la sociedad, la gente se reúne en los lugares a comer, a beber, pero sin hablar, así se establecen en un tipo de relación en la que se mantienen como desconocidos, entonces sólo la vista es lo que apenas los conecta, produciendo una poética con la forma del collage, y ¿qué estética se puede hacer si el otro permanece como un extraño?

En el último verso de la anterior estrofa, el poeta hace alusión a la moneda disoluta, porque el dinero hace que la gente corra en las calles, viviendo con afán, pensando que el tiempo es oro, además que la otra persona sea valiosa según la moneda que tenga. La soledad, entonces, se va entrelazando a la concepción del tiempo y a la mirada de producción y mercado capitalista.

¿Se puede pensar al otrofuera del marco de la producción? Ahora volteemos la pregunta ¿nos podemos pensar a nosotros mismos fuera de este marco?

En el poema "Transito" continúa con la misma temática:

Desde mi ventana los veo, a los ebrios, a quienes

Les crece la barba con un dulce descuido.Los veo mientras ellos me ven girar como una luna [...] (Echavarría , 2004, p. 30).

La experiencia es superficial hacia los demás seres, la vista sólo puede capturar imágenes que se desvanecen y se yerguen a sí mismas como pompas de jabón, enumeración de miles de cosas que habitan la calle, y el poeta se fija en ellas para nombrarlas, sólo para nombrarlas porque le está vedado conocer al otro.

La fragmentación, podría decirse que es el reflejo de una vida basada en el rompecabe- 
zas del caos, el cual hace que la velocidad de la cotidianidad no permita el detenerse; sólo vivir en el instante sin preguntarse nada, en la invivible ciudad fragmentada. En el poema 1 p.m. de José Manuel Arango, se encuentra al poeta que sólo percibe instantes que no están conectados, son una serie de lugares y de situaciones que al parecer no llevan a ninguna parte. Sin embargo, describen a la ciudad y quizá a la cotidianidad del transeúnte, es decir, fragmentos; trozos de cristal que se hallan en el suelo sin posibilidad de ser reconstruidos:

\section{1 p.m.}

En la cuneta el perro envenenado muestra sus dientes amarillos. Verano.

Un sol de cobre que aporrea la nuca y las caras aniñadas de los soldados bajo los cascos.

Notarías, casas de putas, bancos funerarias.

Los saltimbanquis, con sus ropas ceñidas

Como de bailarines o de mimos,

Piruetean. Son los juglares de hoy. Prepara una moneda para echar en la gorra.

Mira a los que los miran. Considera esos rostros atravesados

Por una mueca rencorosa.

Bajo la suela sentirás el asfalto quemándote la planta.

Respira la aridez del aire, el olor a betún, el polvo.

El viento trae un olor nauseabundo de los basureros.

Mediodías como olas de fuego sobre los tejados.

Un gallinazo vuela siguiendo la curva del río. [...] (Arango, 2003, p. 271).

La mirada no puede permitir encontrarse con el otro, por eso la experiencia de observar lo lleva a la fragmentación, es decir, a la fractura entre el "yo" y los "otros". La mirada no puede conocer la historia que se teje de las personas que lo atropellan en las calles, o se aglutinan en los medios de transporte cerca de él. El poeta sólo puede construir una sombra de los síntomas que aparecen en su rostro y en su corto actuar frente a él como observador. En ese sentido su experiencia sería como la de entrar a un lugar lleno de marionetas. Su silencio estaría colmado de un vacío existencial, hallándose en medio de muertos vivientes y sintiendo siempre una extrañeza como observador.

La ciudad se vuelve paradójica, ofrece miles de seres que se cruzan con uno pero que, con- trariamente, siempre son desconocidos. Los peatones se asemejan a unos sapos los cuales les han puesto miles de moscas muertas amarradas de unos hilos, muriendo de inanición porque sólo pueden cazar las cosas que se mueven, de ese modo se ofrece el otro en la ciudad.

\section{El Poema Collage: una experiencia de la modernidad}

La forma poética del collage corresponde a las enumeraciones de diferentes cosas, asuntos y lugares de la ciudad. El cual se genera por la experiencia estética del transeúnte que solo puede partir de la mirada, actitud que se vuelve particular en el poeta porque intenta conquistar al otro pero al no haber diálogo tiene que conformarse con contemplarlo detenidamente, única posibilidad de acortar esta distancia de la incomunicación y el no reconocimiento de los demás.

El poeta se diferencia del transeúnte normal, el cual pareciera estar corriendo en la calle, entre su afán y sus asuntos personales, sin detenerse a mirar, pues le está vedado con la actitud mercantil y pragmática, el comunicarse y el observar detenidamente al otro.

Proust se había encontrado con el problema de las sensaciones de las cosas como una expe- 
riencia en el que se presentan cosas inconexas, en la novela Por el Camino de Swann el personaje se encuentra en un tren observando a través de la ventanilla a personas y cosas que no tienen relación y en las que no puede ahondar. Muchas de ellas condenadas al olvido "tragedia del tiempo" donde las cosas se escapan y perecen porque el conocimiento de la vida es más efímero que eterno.

La experiencia cómo puede tener sentido si las sensaciones de las que se alimenta, todas son inconexas. Proust soluciona el problema con el descubrimiento de la memoria involuntaria, pero el problema continúa con otros matices en la experiencia del transeúnte en la ciudad. Por eso se ahonda con aquello de lo que tanto huyó Proust, con la pérdida de sentido.

El poeta que es un transeúnte se encuentra solo, fragmentado del mundo e imposibilitado de conocer a los demás, y fuera de eso, se encuentra con otros seres que en su afán y mirada mercantilistas pasan afanados, seres que no se detienen, exilian la lentitud al estar aferradas al capitalismo, se convierten en sujetos monadas o seres atomizados. Personas que se miran pero no se hablan. Así, Rogelio Echavarría con su poema El Transeúnte evidencia de forma clara esta fragmentación:

\section{El transeunte}

Todas las calles que conozcomson un largo monólogo mío, mllenas de gentes como árboles batidos por oscura batahola.

O si el sol florece en los balcones y siembra su calor en el polvo movedizo, las gentes que hallo son simples piedras que no sé por qué viven rodando.

Bajo sus ojos - que me miran hostiles como si yo fuera enemigo de todos- no puedo descubrir una conciencia libre, de criminal o de artista,

pero sé que todos luchan solos

por lo que buscan todos juntos.

Son un largo gemido todas las calles que conozco (Echavarría, 2004, p. 25).

Todos nos vamos volviendo cada vez más anónimos y queremos encontrar un puente con el otro, nos sentimos impares; pero aun así, vivenciamos la paradoja como transeúntes de estar con los otros pero sentirnos realmente solos, la mirada recorre el mundo, y los otros son ajenos, anónimos.

\section{La Cosificación del otro}

La sociedad ha perdido el sentido tribal y el concepto de comunidad de las tribus indígenas o las sociedades antiguas. El sujeto no se siente parte de un todo, más bien es un exiliado en su propia tierra, en su propia ciudad, al lado de los hombres que tienen sus mismas costumbres y cultura.

En este sentido, la soledad con características de anonimato, de fragmentación, de individualismo, pertenece no a una cultura universal y existencial del hombre sino a un momento histórico, a una estructura social que lo sitúa en esta posición frente al mundo.

Ahora bien, se pone de manifiesto otra cultura (indígena, tribal) no para idealizarla y contraponerla como algo bueno, lo cual sería tomar una postura anticrítica y simplista. Precisamente el hombre moderno pierde su capacidad de verse a sí mismo, cuando las culturas del mundo han sucumbido en la homogenización y al tener que permearse a la ética capitalista, porque de lo contrario la soledad, la naturaleza, el otro, la identidad y todos los temas metafísicos de la existencia tendrían una variabilidad según la cultura.

Es diferente la concepción que se puede tener del cuerpo en una cultura en la que el Kama Sutra propone que la sexualidad es una forma de llegar a Dios y 
que para la sociedad occidental de cierta forma sigue siendo un tabú; un pecado.

La diversidad cultural permite matizar los conceptos y dar cuenta de la estructura social y de las particularidades del sujeto que emerge en ese mundo a diferencia de otros sujetos y culturas. Sin embargo, la multiculturalidad y la heterogeneidad, son muy complejas. Pues, el reconocimiento al otro es cada vez más difícil en el mundo moderno, lo más probable es que se convierta en una utopía.

La estructura capitalista cosifica al ser humano; las relaciones de comercio ya no se basan en un intercambio donde se reconoce el trabajo en la mercancía, y donde sólo se satisfacían las necesidades más inmediatas. Contrario a esto, el dinero se convierte en el eje rector de la vida de las personas que solo se limitan a consumir desaforadamente dejando de lado a lo humano para convertirse en elementos de la sociedad de consumo masivo. Así mismo, el otro se transforma en un medio para obtener un fin, en el instrumento que cosifica y es cosificado, pues ya no es reconocido por lo que es sino por lo que se tiene y puede dar, se valora al otro en términos de consumo que es lo que establece el estatus y el reconocimiento en la sociedad.

"Si eres productivo y útil haces parte del entramado de individuos que, paradójicamente, se relacionan meramente con la gente en torno al fetichismo y la utilidad, más no reconoces a los demás en términos societarios y más humanos".

La mirada mercantil solo ve objetos y lo demás no se ve, esa es la ceguera moderna. Lo anterior es una explicación que hace Marx de lo que es el capitalismo, su crítica consiste en mirar de qué forma este sistema deshumaniza al hombre, y de qué forma lo cosifica. Si el otro ser humano con el que se interactúa en la vida pública es un vendedor, un chofer, un panadero, el nexo con ellos nos hace verlos como seres que cumplen la función de servir, lo que se desea socialmente es que al entrar en los lugares que trabajan, ellos cumplan a cabalidad su función, pues, su historia y su vida la verdad no importan.

Entonces, la experiencia moderna ve al otro ser humano como objeto. El otro es un elemento que debe cumplir su función, en esa medida ¿qué particularidad tienen los seres que nos rodean?, no se desea escucharlos, conocer su historia, sus angustias, no se los reconoce más allá de su función pragmática.

El hombre-máquina es el hombre que cumple funciones $y$ tiene una mirada práctica de la vida, el que ve la realidad concretamente y observa con atención cómo sacar provecho de las circunstancias y de los otros, así como crear nuevas necesidades para tener riqueza y dedicarse a producir y acumular dinero.

¿Será que el capitalismo puede tener un poco de humanismo? Quizá pensar en la producción y a la vez, considerar las tragedias, sufrimientos y sueños de los trabajadores de la empresa. O, posiblemente, la misma estructura capitalista es deshumanizada y cosificadora, y totalmente excluyente.

Ahora bien ¿qué hace el poeta en un mundo en donde los individuos viven en este afán e imaginario de riqueza y consumismo? Deambular en la calles, más solo que los demás, pues, con su mirada estética es exiliado por los otros transeúntes pragmáticos, entonces tal vez se dedique a escandir las paradojas de la existencia capitalista y escribir con su pluma revolucionaria.

El poeta no se desintegra de la estructura de la sociedad sino que, antes, logra tallar la problemática de sus contemporáneos.

La paradoja de la soledad, estar con los otros sin poder estar con ellos.

"pero sé que todos luchan solos por lo que buscan todos juntos”. 
Echavarría (2004).

El poeta se encuentra consigo mismo, su pensamiento es una espiral que se enrosca en sí mismo, lo cual es una etapa importante en la formación de la consciencia, pero ¿ dónde queda la espiral que permite al poeta aprensar al otro?

“Todas las calles que conozco son un largo monólogo mío" Echavarría (2004).

Las personas están ciegas, sosegadas, pasan sin mirar, no tienen tiempo ni de esto, porque están carcomidas por el afán, ¿y cuál es su afán y su prisa? ¿Cuál es tan importante urgencia? No lo saben, simplemente van con afán, quieren llegar a su casa y pasar el cerrojo y descansar.

Entonces, vemos que el poeta es un transeúnte que mira pero que se choca con otras miradas que no desean mirar porque todas las cosas que trascurren en la calle no tiene valor para él, entonces ¿qué es lo que tiene valor para esos transeúntes? Tal vez se ha introducido en ellos el valor de cambio, el símbolo de las mercancías, y lo demás no tiene valor si no entra en este marco.

El poeta se siente ajeno a esta cotidianidad donde es un extraño entre tanta gente que vive para la sociedad de consumo, contempla y analiza con angustia esta situación que lo lleva a repensar su existencia frente a la de los otros, se siente cuestionado y presionado a hacer parte de tan maquiavélica forma de existir, es allí donde en su obra denuncia y reclama a los seres que corren sin cesar para que se detengan y clama una humanidad más humana.

Sin embargo, la indiferencia se encuentra inmersa en la ceguera de la gente, esa que no les permite reconocer al que va a su lado, ni percibir con las personas que chocan, sin importarle lo que le suceda a los otros, tanto así que pueden pasar por encima de los demás sin percatarse. Así como en el poema El enigma, el hombre es halado de sus hilos invisibles por quien le hurta su equilibrio; este cae y no es auxiliado por nadie. Pide ayuda, mientras ve como los demás pasan por su lado sin reconocerle, pues se encuentra segregado por su condición desequilibrada y marginal.

En el siguiente poema todas las personas videntes parecen más ciegas que la persona que no puede ver, pues paradójicamente el ciego conoce la tez de los jazmines y las piedras del camino y perdona a los otros videntes por no verlo.

\section{Ved}

Ved al ciego que va voceando su haz de prensay a su pequeña hija miserable, engendradala misma noche que hoy tiene diez años. (Todos engendramos nuestros lazarillos).Vedlo

vendiendo luz a los que pasan por un valor de cobre de rutina.

De las floristerías sale un olor a muerto, mas él conoce sólo la tez de los jazmines que riega la pequeña en su jardín errante; y el pulso que adivina las piedras del camino pide, torpe, a los cielos su última moneda.

En esta encrucijada en que se anuda el tránsito en urbano remolino, los dedos de la niña tejen el verde paso y, náufrago en los hombros de los rudos peatones, el ciego les perdona a los hombres no verlo, mientras sigue buscando sus pupilas caídas entre el polvo de estrellas sin distancia (Echavarría, 2004, p. 27).

Ciegos, hombres que sólo ven dinero y no a otros hombres, pasan afanados y nada más les importa, corren como piedras lastimándose su alma, pisan al otro, a la estética y al arte. Mudos en su afán transitan la ciudad con pesadez y se ríen del poeta que quiere detenerse, observar, y hablar con los demás. 


\section{la palabra}

\section{Referencias}

Arango, J. M. (2003). Poesia Completa. Medellin: Universidad de Antioquia. p. 271.

Echavarría, R. (2004). El Transeúnte (1947-2003). Medellín: Universidad de Antioquia. pp. $25,27,30,39$.

Echavarría, R. (1955). 4, Octubre/Noviembre de 1955, Mito, Vol. 1, pp. 226-227.

Vidales, L. (2004). Suenan timbres. Bogotá: Universidad Nacional de Colombia. p. 58.

Rivero, M. (2001). Poemas urbanos. Bogotá: Arango. 